\title{
Como Certificar o \\ Turismo Sustentável?
}

How to Certify Sustainable Tourism?

Mário Carlos Beni ${ }^{1}$

RESUMO: Este artigo contém a síntese das contribuiçōes prestadas pelo autor na Conferência Regional das Américas realizada de 29 a 30 de setembro de 2003 na Costa do Sauípe, Bahia, bem como suas críticas e recomendações. $\mathrm{O}$ assunto até agora não alcançou consenso, ainda mais quando se leva em conta a não-participação da universidade e dos centros de pesquisa em sua discussão e formulação e, por isso, a ênfase sempre recai na preservação e na defesa do meio ambiente. A pergunta contida no título é instigante e até serve de estímulo para ousados trabalhos e pesquisas. Para orientar o leitor, há também uma breve síntese do histórico da problemática ambiental e sua evolução até as tentativas atuais para construir o conceito de turismo e desenvolvimento sustentável.

PALAVRAS-CHAVE: turismo sustentável; eco-sustentabilidade do turismo; certificação.

ABSTRACT: This paper contains a synthesis of contributions presented by the author at the Regional Conference of the Americas that took place in Costa do Sauipe, Bahia, September 29-30, 2003, as well as critical remarks

1. Engenheiro Civil pela Universidade Mackenzie; Mestre em Ciências Sociais, Doutor em Ciências da Comunicação, Livre-docente e Professor Titular da ECA-USP; professor do curso de mestrado em Hotelaria e Turismo da Universidade do Vale do Itajaí (Univali), Santa Catarina, e dos cursos de pós-graduação e mestrado em Turismo na Universidade de Caxias do Sul (UCS), Rio Grande do Sul. Contato: Av. Prof. Lúcio M. Rodrigues, 443 - Bloco B - 05508-900 - São Paulo - SP; e-mail: beni@usp.br. 
and recommendations. The subject matter has not reached a consensus until now, mainly due to the lack of participation of universities and investigative centers in its discussion and formulation, therefore with emphasis always returning to preservation and environment issues. The question incorporated in the title is inciting and serves as an encouragement for more daring works and investigations. To guide the reader there is also a short synthesis of the history of the environmental problem and its evolution until the present attempts to build the concept of tourism and sustainable development.

KEYWORDS: sustainable tourism; eco-sustainability of tourism; certification of sustainable tourism.

\section{Introdução}

As complexas e muitas vezes conflitantes interrelações do homem com o meio ambiente assumem, a partir do século passado, feições várias de interesse planetário, eis que os países desenvolvidos despertaram para o trato metodológico desse binômio atividade humana x preservação do meio ambiente.

As ações antrópicas em seus impactos negativos nos ecossistemas dominaram o panorama e hoje não mais atingem limites geofísicos e socioculturais mas toda a humanidade praticamente.

Das discussões sobre ecologia, que abriram o terreno para o exame dessas inter-relações, o que se tem atualmente em maior destaque e relevância é o turismo sustentável, expressão esta que abriga infindos posicionamentos políticos e geoestratégicos até interesses imediatos para navegar na onda de um tema tão sério e complexo quanto fluido em seus aspectos práticos.

O Turismo vem-se firmando como ciência humana e social. Porém seus efeitos econômicos são os que habitualmente mais se destacam, merecendo não só a atenção maior de pesquisadores e empreendedores, como também maior e melhor tratamento estatístico.

O objeto de estudo do Turismo é próprio e nele se congregam também variáveis e métodos de análise de outras ciências mais tradicionais e consolidadas. Essa conexão, além de conferir-lhe interdisciplinaridade, possibilitou, ao longo do processo de seu desenvolvimento, que o Turismo atingisse mais amplitude e modernidade, podendo ser hoje definido como ciência da expressão do homem no mundo global, competitivo, e que quer transcender rumo a uma nova visão de valores universalistas.

É importante lembrar, ainda, que o turismo começa a superar o qualificativo de setor estanque, exclusivo, pois em virtude do processo de globalização, em que foi instrumento de destacada contribuição, está sempre presente como fun- damento na formulação, elaboração e execução de muitas políticas econômicas, regionais, sociais e culturais de vários países.

O equilíbrio pretendido entre a atividade humana e o desenvolvimento e a proteção do ambiente exige uma repartição de responsabilidades eqüitativas e claramente definida com relação ao consumo e ao comportamento face aos recursos naturais. Isto implica a integração de considerações ambientais na formulação e na implementação das políticas econômicas e setoriais, nas decisões das autoridades públicas, na operação e no desenvolvimento dos processos de produção e nos comportamentos e nas escolhas individuais. Implica igualmente a existência de um diálogo real e a pactuação de ações de parceiros que podem ter prioridades de curto prazo diferentes; tal diálogo terá de ser apoiado por informação objetiva e crível.

Assim, a palavra sustentabilidade pretende refletir uma política e estratégia de desenvolvimento econômico e social contínuo, sem prejuízo do ambiente e dos recursos naturais, de cuja qualidade depende a continuidade da atividade humana e do desenvolvimento.

Acompanha-se com vivo interesse e, ao mesmo tempo, com preocupação crescente, a questão da sustentabilidade das atividades turísticas, louvando sempre o destaque e a importância que esse tema vem ganhando em pesquisas, seminários e publicações.

Uma questão conceitual, porém, continua trazendo inquietações compartilhadas freqüentemente com colegas da Aiest, que também se manifestam com semelhantes preocupações.

Pelas observações e leituras constatadas, todos os pesquisadores e autores que se dedicam ao estudo do tema são unânimes em afirmar que sustentabilidade é um conceito que envolve o longo prazo, que gera valor agregado por meio de lei de otimização e não da maximização da renda, assegurando a inclusão e a coesão social e política num processo de desenvolvimento integrado e integral.

Aqui deve-se lembrar, em linhas gerais, o histórico da problemática ambiental e sua evolução até as tentativas atuais para construir o conceito de turismo e desenvolvimento sustentável:

- 1972 - Conferência da ONU sobre Meio Ambiente Humano em Estocolmo: primeira iniciativa do gênero para examinar a questão de maneira global e coordenada na busca de soluções aos problemas existentes e definir linhas de ação para a problemática ambiental;

- 1974 - Ignacy Sachs e sua equipe interdisciplinar, sediada no Cired Centre International de Recherche sur l'Environnment et le Dévéloppement, reelaboram a questão do ecodesenvolvimento, criada em Estocolmo em 1972, ampliando e diversificando seus horizontes; 
- 1974/1975 - Com a Declaração de Cocoyoc de 1974, e o Relatório Que Faire apresentado no final de 1975 pela Fundação Dag Hammarskjold, por ocasião da 7a Conferência Extraordinária das Nações Unidas, reutilizaram as idéias de Sachs e sua equipe, sem utilizar contudo o termo "ecodesenvolvimento" de forma explícita mas as expressões "um outro desenvolvimento" " "desenvolvimento sustentado";

- 1982 - Em Nairóbi, Quênia, sede do Programa das Nações Unidas para o Meio Ambiente - PNUMA, realizou-se reunião comemorativa do $10^{\circ}$ aniversário da Conferência de Estocolmo, quando procedeu-se à avaliação do resultados até então obtidos e a um exame da mudança de percepção da problemática ambiental;

- 1983 - Em resposta a uma decisão da Assembléia Geral da ONU, foi estabelecida a Comissão Mundial sobre Meio Ambiente e Desenvolvimento, presidida pela norueguesa Gro Brundtland. O objetivo amplo foi reexaminar a questão ambiental, inter-relacionando-a com a questão do desenvolvimento, e propor programas de ação. Quatro anos depois elaborou-se o relatório final da comissão, intitulado Nosso Futuro Comum, conhecido também como Relatório Brundtland. Desse relatório surge com mais força a expressão "desenvolvimento sustentável", com intenção de despertar a conscientização pública e evidenciar a necessidade de um melhor gerenciamento do meio ambiente para sustentar o planeta Terra;

- 1992 - Muitas das idéias e percepções do Relatório Brundtland foram discutidas na Rio-92. Entre as principais destacam-se: a Carta da Terra, uma declaração de princípios básicos a serem seguidos por todos os povos com respeito ao meio ambiente e ao desenvolvimento; e a Agenda 21, um plano de ação com as metas aceitas universalmente para o período pós - 1992 e entrando pelo século XXI.

Em abril de 1995, por iniciativa da ONU, realiza-se a Primeira Conferência sobre Turismo Sustentável, em Lanzarote, nas Ilhas Canárias. Foi co-patrocinada pelo Programa Ambiental dessa mesma organização, e pelo Programa sobre o Homem e a Biosfera da Unesco e pela OMT.

Uma das principais preocupações do Encontro foi a observação que expressou a maioria dos participantes, de que a iniciativa privada, à época, pouco se sensibilizava com os programas e as ações de preservação ambiental.

De Estocolmo até a Rio-92 destacou-se a polarização desenvolvimentista, formada pela riqueza dos países desenvolvidos ou industrializados do Norte e pela pobreza dos países em desenvolvimento ou do terceiro mundo do Sul.
Observou-se, nesse evento, a introdução de novos conceitos, como certificação ambiental, atuação responsável e gestão ambiental, que buscavam mudar a postura reativa que marcava até então o relacionamento entre as empresas, de um lado, e os órgãos governamentais, de ordenamento, normalização, legislação e fiscalização e as instituições ambientais, notadamente as ONGs, de outro.

Intenta-se, pois, uma nova atitude baseada na responsabilidade solidária, que relega a um segundo plano as preocupações com multas e auto-ações que vão sendo substituídas por um maior cuidado pela imagem das empresas, com conseqüente valorização e reconhecimento de seus programas ambientais.

Nesse mesmo ano, assiste também à entrada em vigor das normas britânicas (BS 7750) Especification for Environmental Management Systems que serviriam de base para a elaboração de um sistema de normas ambientais em âmbito mundial. A entrada em vigor dessas normas internacionais de gestão ambiental, denominadas de série ISO-14000 e sua já anunciada integração futura com as normas de gestão de qualidade (ISO-9000), constituíram o coroamento de uma longa caminhada em direção da conservação do meio ambiente e do desenvolvimento em base sustentável.

Em 1997 já haviam sido emitidos 4.433 certificados ISO-14001 em 55 países. Em 1998, esse número passou para 7.887 certificados em 72 países, estando 6.786 dessas empresas situadas na Europa, Extremo Oriente e Sudeste Asiático. Até fins de 2000, 22.897 empresas no mundo, distribuídas por 98 países, estavam com sistemas de gestão ambiental certificados pela Norma ISO-14001.

\section{A Visão Interdisciplinar de Ignacy Sachs Sobre Desenvolvimento Sustentável}

Sachs reelabora o conceito de desenvolvimento sustentável, também chamado de ecodesenvolvimento, como um estilo de desenvolvimento aplicável a projetos não só rurais mas também urbanos, oposto à diretriz mimético-dependente tradicionalmente adotada nos países pobres, orientado pela busca de autonomia ou self-reliance, e pela satisfação prioritária de necessidades básicas das populações envolvidas. A integração da dimensão do meio ambiente é pensada não apenas como uma espécie de co-ação suplementar, mas também na qualidade de um amplo potencial de recursos, utilizando-se de critérios de prudência ecológica.

Sachs articula quatro postulados, reunindo idéias essenciais do enfoque do desenvolvimento sustentável. O primeiro deles é a prioridade ao alcance de finalidades sociais, redirecionando o processo de crescimento econômico, visando o alcance de objetivos sociais prioritários, traduzidos pelas suas necessidades mate- 
riais e psicossociais, como autodeterminação, participação política e auto-realização; o segundo é a valorização da autonomia ou self-reliance, buscando um maior grau de controle dos aspectos cruciais do processo de desenvolvimento, mediante a ação da sociedade civil organizada, no âmbito local, microrregional ou regional, canalizando e maximizando os seus recursos disponíveis num horizonte de respeito às suas tradições culturais e sem incorrer, com isso, em auto-suficiência ou isolacionismo; o terceiro é a busca de uma relação de simbiose com a natureza, abandonando o padrão arrogante de relacionamento com o meio ambiente biofísico instaurado pela modernidade à luz do processo modernizador; e o quarto é a eficácia econômica, situando a eficiência econômica como uma alternativa à racionalidade microeconômica dominante, no sentido de uma internacionalização efetiva da problemática dos custos socioambientais do processo de desenvolvimento.

Pode-se, também, reagrupar estes postulados do desenvolvimento sustentável de maneira a conceituá-los mais adequadamente em termos de estratégias de um desenvolvimento socialmente mais justo, ecologicamente prudente e economicamente eficaz.

\section{Planejamento para o Desenvolvimento Sustentável}

Sachs aponta que o desenvolvimento sustentável deve ser implementado por uma metodologia de planejamento, como sendo um espaço de aprendizado social, eqüidistante tanto da tradição tecnicista quanto da assembleísta, e materializando-se sobre uma síntese pedagógica.

É nesta ótica que o planejamento oferece um novo modelo para políticas governamentais, com estratégias concretas de intervenção corretivas baseadas nos postulados interdependentes de eficiência econômica, eqüidade social e prudência ecológica, e um novo critério de racionalidade social com base na crítica ao efeito de externalização de custos socioambientais, exercido pelo modelo puramente econômico, sobretudo quando este planejamento é participativo, com atores sociais, agentes e reagentes, com uma visão contratual com o meio ambiente.

O planejamento participativo recupera a participação social da sociedade, de modo que o cidadão contribua na elaboração das ecoestratégias desde a informação até a execução da ação proposta, transformando a sociedade civil num terceiro sistema à medida que toma consciência de si mesma e começa a interpelar-se e a conhecer-se.

Na elaboração das ecoestratégias do desenvolvimento, o planejamento trata de algumas dimensões de sustentabilidade, conforme as idéias de Sachs no seu trabalho mais recente:
1 - Sustentabilidade Social: é a criação de um processo de desenvolvimento civilizatório baseado no ser e que seja sustentado por uma maior eqüidade na distribuição do ter, nos direitos e nas condições das amplas massas da população, e achatar a distância entre os padrões de vida dos mais ricos e mais pobres.

2 - Sustentabilidade Econômica: possibilita uma melhor alocação e gestão mais eficiente dos recursos e por um fluxo regular do investimento público e privado. Esta eficiência é macrossocial, reduzindo os custos sociais e ambientais, bem diferente da lógica economicista.

3 - Sustentabilidade Ecológica: incrementa o aumento da capacidade de recursos naturais, limitando os recursos não-renováveis ou ambientalmente prejudiciais, reduzindo o volume de poluição, autolimitando o consumo material pelas camadas sociais mais privilegiadas, intensificando a pesquisa de tecnologias limpas e definindo regras para uma adequada proteção ambiental.

4 - Sustentabilidade Espacial: é aquela voltada a uma configuração ruralurbana mais equilibrada com ênfase nas seguintes questões: concentração excessiva nas áreas urbanas, processos de colonização descontrolados, promoção de projetos modernos de agricultura regenerativa e agroflorestamento, industrialização centralizada, criação de empregos rurais nãoagrícolas, e o estabelecimento de uma rede de reservas naturais e de biosfera para proteger a biodiversidade.

5 - Sustentabilidade Cultural: engloba as raízes endógenas dos modelos de modernização e dos sistemas rurais integrados de produção, respeitando a continuidade das tradições culturais, e até mesmo a pluralidade das soluções particulares.

6 - Sustentabilidade Política: privilegia a negociação da diversidade de interesses envolvidos em questões fundamentais desde o âmbito local ao global.

Observa-se que, paralelamente aos eventos já relatados no histórico da problemática ambiental, surgiram, nesse mesmo período, instituições internacionais de defesa, preservação ecológica e certificação ecológica, como a World Wildlife Foundation, o Green Globe, a Forest Stewardship Council, o Greenpeace, a International Hotel in Environmental Iniciative, a Rainforest Alliance, a International Ecotourism Society, a CST - Certificación para la Sostenibilidad Turística, o CSD Centro de Estudios de Ecoturismo para el Desarollo Sostenido, a FUNBIO, o ECOBRASIL, o S.O.S. Mata Atlântica, dentre outras. No Acordo de Mohonk, EUA, foi sugerido o estudo de um processo unificado de certificação mundial. 
É importante destacar que, até então, todas essas organizações trabalhavam e ainda hoje trabalham exclusivamente com metodologia e parâmetros de qualidade, preservação e sustentabilidade ambiental, sem se aprofundarem em estudos e pesquisas econômicos e político-sociais, sempre resistindo à inclusão do Turismo na ocupação dos espaços naturais e de áreas protegidas, limitando-se ao estudo de seus impactos nesses locais.

Destaca-se, portanto, ao se utilizar agora o conceito de turismo sustentável, cogitando-se até de sua certificação, a necessidade de maior reflexão sobre a abrangência do que até então se vinha entendendo por sustentabilidade ambiental ou ecosustentabilidade, econômica e social, o que já evidencia a complexidade e a amplitude do universo a ser certificado.

Não podemos, a essa altura, confundir Sustentabilidade Ecológica do Turismo com Turismo Sustentável - a sustentabilidade ecológica ("licenciamento ambiental", "qualidade ambiental", "gestão ambiental", "desenvolvimento ambiental sustentável”) é apenas um dos cenários da sustentabilidade do Turismo.

Convém lembrar que muitos pesquisadores e autores, dentre os quais o autor se inclui, vêm chamando a atenção para a controvérsia gerada pela expressão "desenvolvimento sustentável" e que alguns vão ainda ao extremo de designar desenvolvimento sustentado; o que na realidade se depreende é que a literatura sobre o tema aponta que inexiste consenso em torno da definição de desenvolvimento sustentável e que sua interpretação depende muito da ótica de quem dela se utiliza. As ambigüidades do conceito de sustentabilidade, hoje rótulo aplicado indiscriminadamente, servem a muitos propósitos, como definir o que é uma sociedade sustentável e Turismo Sustentável. Um exemplo é o Programa de Certificação em Turismo Sustentável, iniciativa brasileira que está sendo implementado numa ampla parceria com as empresas do setor de turismo, governo federal, instituições organizadas da sociedade civil, municípios e comunidades sob a liderança do Instituto de Hospitalidade por intermédio do referido Programa (www.pcts.org.br) e em conjun to com o Conselho Brasileiro de Turismo Sustentável CBTS (www.cbts.org.br).

Partindo dessa questão, deve-se lembrar que o desenvolvimento sustentável é um conceito útil à medida que aponta para a necessidade de reflexões ao estabelecimento de uma visão da estrutura da organização da economia, da sociedade e de suas relações de troca com o meio ambiente.

Pela complexidade e abrangência desses pressupostos da sustentabilidade, como se referir e assegurar uma certificação em turismo sustentável? A certificação ambiental vem-se revelando um importante instrumento de política ambiental, auxiliando o consumidor na escolha de produtos e serviços menos nocivos ao meio ambiente, e servindo de instrumento de marketing para as empresas que diferenciam seus produtos no mercado, atribuindo-lhes um plus em sua qualidade.
A ecocompatibilidade dos produtos passa a ser, então, além do preço, uma referência na oferta de consumo.

As práticas ambientais por uma empresa resultam de, pelo menos três grupos de fatores: a regulamentação pública; as pressões exercidas pela sociedade, principalmente por meio dos segmentos organizados que atuam no meio ambiente, de defesa do consumidor e dos direitos humanos; e as pressões exercidas pelas relações entre empresas e entre estas e consumidores.

A crescente responsabilidade das empresas com os problemas ambientais, as auditorias ambientais voluntárias, os eco-selos que endossam a compatibilidade ecológica dos produtos, a expansão do ecobusiness, podem induzir, por si só, uma qualidade ambiental.

É possível falar sim em turismo sustentável, ao discutir suas normas para os meios de hospedagem, quando referir-se à inserção de aspectos ambientais na política de gerenciamento desses empreendimentos, isto é, gestão ambiental dos meios de hospedagem. Então, a partir daí, poder-se-á pensar em certificação e selo de qualidade, como o já praticado desde 1978 na Alemanha quando surgiu o primeiro selo ecológico, o Anjo Azul, destinado a rotular hotéis ambièntalmente corretos.

As políticas públicas de Turismo precisam ser repensadas em função da própria dinâmica da atividade, da necessária reflexão e da reformulação das estratégias de desenvolvimento sustentável, ora voltadas à regionalização, precisando superar as principais dificuldades e os obstáculos à ação integrada e intersetorial que se impõe aos sistemas institucionais oficiais públicos de turismo. A proposição de um sistema integrador ágil e instrumentalizado deve ser capaz de conciliar diversidades territoriais e rivalidades intermunicipais numa mesma região para obtenção de maior equilíbrio e competitividade nesse espaço, e para assegurar a correta aplicação dos investimentos públicos para a promoção do desenvolvimento sustentável ambiental, econômico e político-social, juntamente com a conseqüente e necessária orientação aos empreendimentos da iniciativa privada.

É fundamental destacar que vivem-se tempos de transformação, isto é, passa-se de um modelo burocrático, prestador e concessionário de serviços, para um modelo empreendedor, de co-responsabilição social solidária, a que o Estado deve prestar decisiva colaboração em conjunto com as empresas privadas e as organizações sociais. Tal ação interativa certamente representará um esforço ponderável na construção de um modelo de desenvolvimento integral, integrado e sustentável, possibilitando superar paulatinamente a reprodução da pobreza e da exclusão social provocadas pelo aumento das desigualdades, da internacionalização da economia, da incontrolada competitividade e do esgotamento das verbas públicas. Nesse processo integrado, ou novo planejamento, a ênfase recai na observação rigorosa de possíveis conseqüências das políticas alternativas am- 
bientais, econômicas e político-sociais para, somente então, após avaliá-las em profundidade, optar pelas medidas recomendadas e os processos adequados.

Uma ordenação sustentável do território, que parece estar sendo interpretada e focalizada apenas e tão-somente na dimensão ambiental quando se refere ao turismo sustentável, é a que alia o ótimo idealizado para o homem com a apropriada preservação da natureza por meio de relações harmônicas.

Sem dúvida, isso exige solução a um reiterante desafio aos planejadores do desenvolvimento sustentável e aos empresários que investem sem estruturarem seus empreendimentos na essencialidade desses conceitos, na viabilidade das projeções de mercado, pois historicamente a seletividade na ocupação e na organização do espaço, ou ordenação do território, foi e continua sendo determinada predominantemente pelos interesses econômicos de curto prazo, deixando de lado as questões de preservação ambiental e de inclusão social.

Hoje existe um consenso mundial de que o turismo tem de firmar-se em quatro pilares:

- o ambiental, principal fonte de matéria-prima dos atrativos;

- o social, e aí entende-se, em sua abrangência, a comunidade receptora, o patrimônio histórico-cultural e a interação com os visitantes, ao mesmo tempo em que eleva o padrão de vida e a auto-estima dessa comunidade;

- o econômico, com todos os inter-relacionamentos e interdependências da cadeia produtiva, permitindo sua articulação com a identificação correta de suas unidades de produção e de negócios para estabelecer uma rede de empresas a fim de atuar, de forma integrada, proativa e interativa, obtendo níveis de comparatividade e produtividade para o alcance de competitividade;

- o político, que se instrumentaliza mediante estratégias de gestão que possibilitem coordenar as iniciativas locais na criação de um entorno emulativo de produção, favorecendo o desenvolvimento sustentável.

Enfim, o Turismo Sustentável, portanto, em sua vasta e complexa abrangência, envolve: compreensão dos impactos turísticos; distribuição justa de custos e benefícios; geração de empregos locais diretos e indiretos; fomento de negócios lucrativos; injeção de capital com conseqüente diversificação da economia local; interação com todos os setores e segmentos da sociedade; desenvolvimento estratégico e logístico de modais de transporte; encorajamento ao uso produtivo de terras tidas como marginais (turismo no espaço rural); subvenções para os custos de conservação ambiental.

Consideradas a importância, a amplitude e a envergadura desses pressupostos básicos do Turismo Sustentável, o autor compareceu, levando sua contribuição e reflexões, à Conferência Regional das Américas promovida pela OMT em con- junto com o Instituto de Hospitalidade, realizada na Costa do Sauípe, BA, de 29 a 30 de setembro de 2003, com o tema central Certificação da Sustentabilidade das Atividades Turísticas. E conjeturou-se: talvez o único lugar das Américas que não deveria sediar um Encontro sobre esse tema seja justamente o complexo turístico eleito que não é, diga-se de passagem, um exemplo de turismo sustentável.

Com mais de 20 países do continente representados, o que se assistiu, mais uma vez, foi a predominância de ambientalistas ligados a órgãos governamentais e instituições voltadas à preservação do meio ambiente. Outros segmentos do setor de turismo pouco se fizeram representar, como também verificou-se a ausência da iniciativa privada.

Participou-se dos grupos de trabalho que envolveram temas como sustentabilidade do turismo e sua metodologia de certificação, análise da certificação com ênfase na América Latina, principais questões e desafios da certificação, sistemas de certificação de sustentabilidade existentes nas Américas, papel do governo na certificação, a ação das instituições internacionais, sistemas de certificação e consumidores, a participação e a visão das empresas de turismo, estratégias de sustentabilidade para micro e pequenas empresas, a acreditação de certificadores, lançamento de rede latino-americana de certificação de turismo sustentável, indicadores de sustentabilidade e sua utilização em certificados e eco-selos. Constatou-se que havia a coordenação e moderação de duas organizações internacionais de preservação ambiental: a Rainforest Alliance e a International Ecotourism Society, designadas oficialmente pela OMT.

Aqui, de novo, causou surpresa o equivocado conceito de turismo sustentável que a própria OMT acolhe, confundindo-o com ecossustentabilidade do turismo. $\mathrm{Se}$, ao menos, esse conceito se referisse à "ecologia profunda", o mais recente, amplo e abrangente conceito de sustentabilidade apresentado e defendido por vários estudiosos, ainda poder-se-ia entender! O que percebeu-se, em todas as discussões, foi a ausência da sustentabilidade social, econômica, cultural e política.

Também foi de estranhar, ao lado dos exemplos e modelos apresentados, a inexplicável não-apresentação do modelo Sebrae de desenvolvimento sustentável de turismo, como o que está em desenvolvimento na Serra Gaúcha, e que, entende-se, é o mais próximo do conceito de sustentabilidade do turismo.

Foi possível introduzir como recomendações uma maior aproximação com as universidades e centros de pesquisa para aprofundar terminologia e conceitos hoje equivocados e adotados indiscriminadamente, bem como questionamento das atuais metodologias e critérios de certificação, sugerindo um debate mais amplo com conceitos mundialmente uniformes e aceitos, os quais deverão fundamentar os métodos e as técnicas adotados para uma eventual certificação setorial do ecoturismo, conforme já realizado e executado nos certificados de qualidade am- 
biental e de desempenho empresarial nas séries ISO-9000 e ISO-14000, assim como a certificação de destino no caso do turismo sustentável.

A proposta brasileira insistiu na certificação de destino, enquanto a maioria dos modelos recomenda a certificação de empresas.

Houve muitos debates e verificaram-se resistências em razão da questão: a quem certificar? A resposta a esta pergunta estaria no âmago do modelo de gestão que, sequer, foi debatido, lembrando que a Espanha tem, no modelo de Barcelona, um dos mais aperfeiçoados paradigmas de desenvolvimento sustentável do turismo; igualmente, o México, presente no evento, nem se lembrou de Cancún, o caso mais famoso de sustentabilidade do turismo.

Não causa mais estranheza, após todas estas observações, ponderações e registros, que Walter Leu tenha escrito:

Sustentabilidade tornou-se, para mim, uma provocação negativa, o rótulo para uma cultura de desonestidade, a representação máxima da adulação. Todos os discursos, todos os artigos, todos os pronunciamentos de políticos ou de profissionais de turismo repetem essa palavra de forma incansável embora, infelizmente, em desacordo com o seu significado e conteúdo reais. (Lockwood; Medlik, 2003: 279)

De pouco vale o conhecimento técnico e científico sem o compromisso do conhecimento ético. Despertar para a ética é acudir a todas as demais necessidades do homem no espaço e suas inter-relações com o meio ambiente, mesmo porque as melhorias necessárias na ética do turismo produzirão inevitavelmente uma acirrada competição de idéias neste século. $\mathrm{O}$ conceito será muito mais importante do que $\mathrm{o}$ próprio produto, imaginam muitos pesquisadores, pensadores e autores de turismo.

\section{Referências Bibliográficas}

BENI, Mário Carlos. 1990-2003. Conferências, debates, mesas redondas e aulas sobre sustentabilidade. Material próprio.

LEU, Walter. In: LOCKWOOD A.; MEDLIK, S. 2003. Turismo e hospitalidade no século XXI. Barueri - SP: Manole. p.279.

SAMPAIO, Carlos Alberto Cioce. 1991. Turismo sob a análise do desenvolvimento sustentável. Turismo: visão e ação, Itajaí: UNIVALI, ano $4, n^{\circ} 8$.

SACHS, I. 2000. Caminhos para o desenvolvimento sustentável. Rio de Janeiro: Garamond. 